\title{
Impact of Technology in Life of a University Student
}

\author{
Ayushmaan Tomar \\ Student, Sri Venkateshwar International School \\ Sector-18A, Dwarka, New Delhi 110075
}

\begin{abstract}
Technology has drastically transformed the culture of education system. Students have access to endless data and information from the ocean of sources called Internet with high speed and reliability. Teachers can perform various calculations, analyze information, visualize educational data and information and can even conduct live classes through various media software. Despite Internet having many constructive attributes, there are few unconstructive aspects also. Due to contemporary trends of online gaming, students are becoming increasingly more addictive towards their electronic gadgets which are hampering their studies. This paper examines the impact of technology on a student. A survey questionnaire was distributed online to various University students through their emails in Delhi-NCR region. The analysis of the survey was processed through WEKA software. The survey concluded the aftermaths of technology as undergraduate students are more prone to spend above $90 \%$ of their time on their smart phones utilizing the internet facilities mainly from home.
\end{abstract}

\section{Keywords}

Internet, Networking, Students, Technology, WEKA

\section{INTRODUCTION}

The evolution of technology has dramatically changed our society. Several people all around the world use and benefit themselves with modern technology as it facilitates us with tremendous opportunities and play a significant role in almost all phases of human life. Nowadays, technology has occupied everyone's attention as every single person is using a smartphone and has access to internet [1].

Education is transformed by technology. Students can get data and information with high speed and reliability. Universities are providing online degree programs. There are many educational tools for teachers on the Internet to use. On the other hand, students are taking online classes, participating in online debates, interviews, forums etc. The impact of technology can be seen in younger generations as they want to earn money online and are looking for passive income sources. That's the power of technology that should be identified and aligned by education authorities.

Education using computer and Internet provide veracity for students. Computers are capable to perform countless tasks thousands of times faster using a specific application. Today's younger generation is more interested in using tech tools. Teachers can transform creativity into student's mind with using technology tools.

The computer helps teachers and students to perform the calculations, analyze information and visualize educational data and information in real time. Students can repeat the process on computers million times as unlike humans it doesn't get bored. Is this possible without computers? Students can believe on computer programs for the better results. For example, if someone is doing the calculation in
Microsoft Excel, they can use formulas to calculate and logics to analyze.

Computer technology in every field helps to get data and information quickly. For example, Google is the greatest source organizing every bit of information and make it useful and accessible to everyone. Technologies provide speed and continuity. Peripheral devices provide storage space that can be used by students and teachers to download videos and project files.

Live classes, summer programs and computerized education etc. are the innovation in education because of the transformation of information technologies. Students and teachers are getting various functions and utilization due to these innovations. There are numerous advantages of online classes and degree programs. All of them are possible because of the integration of technology in learning and communication process.

Uses of technology in education have increased the level of efficiency in educational materials to a higher archetype. Usages of new technologies are expanding to outer realms. New computer programs and mobile apps are playing their role to solve daily life problems and give various solutions.

Using technology in the classroom enables teachers and students to find the new alternatives of various academic problems. Technology helps to create a better educational syllabus, learning material, future products and services. It is important to integrate technology with classroom programs for better understanding.

Technology is very important in education to create new and innovative, security of students, their data management, analysis and performance reporting in accordance teachers training programs. It has inspired many talent people to hone their skills. Creativity and innovation have always made students successful in their career and life.

Classroom Technologies help students and teachers in the process of receiving and giving data and information systematically. Technology helps in facilitating acquisition of knowledge and skills. Educators \& learners around the world can connect and interact with each other on various social media platforms. For such benefits it is important to use technology in education.

Technologies in Students' life have many advantages such as promotes independent learning in students, prepares students for the future, has the potential to lower textbook and tuition prices, allows teachers to create an exciting way to educate students, encourages development of new teaching methods.

But it also has many disadvantages such as results in a lack of interest in studying, makes students vulnerable to potential pitfalls, negative views on technology, raise instructional challenges, can diminish overall value of in-person education.

The mentioned above disadvantages leave a question in our minds: -" Is Technology a good or bad integration in our 
Education?" in Accordance to the above question, in this paper, we will exploit the analysis of use of technology in the life of students in Delhi-NCR Universities. Hence answering the research question: -" What is the use of technology in students' academic performance?"

Today, Indian Education is one of the toughest and greatest in the world. With some of the best colleges and universities, it is renowned for its excellence and high standards. Technology advancement in India has rapidly to transform the way students in India acquire educational content. Additionally, the development of internet-based smartphones has helped to spread quality learning to students across geographies in India.

The Government of India has launched many schemes to provide technological resources to many educational institutes to make Virtual Education accessible to all deserving students. In this regard, they have launched The National Mission on Education through Information and Communication Technology (NMEICT) in 2009 to provide the opportunity for all the teachers and professors in the country to store their collective wisdom and knowledge for the benefit of every Indian learner and, thereby, reducing the digital divide. (MHRD)

Based on the above, we would say that education through the medium of education may be dangerous in some cases, but it has been considered necessary for the learner to develop. Any risks can be eliminated by properly organization and skilled planning.

For example, there could be more and better IT laboratories and campuses in Universities. The halls can be well-equipped to make it much easier for teachers to work and student to learn. Teachers should be trained and informed about all kinds of educational software that exists and can facilitate their lessons. Therefore, Teacher Training is of the utmost importance. Finally, the curriculum of the universities should be complete, successfully integrate in accordance to new technologies, but at the same it must not prevent the professors and students from the freedom of creation.

In all the stated paragraphs above, it is necessary to keep on innovating new technologies integrating it with education system providing with the greatest success in education and leading to the proper development of the students and the path of creativity.

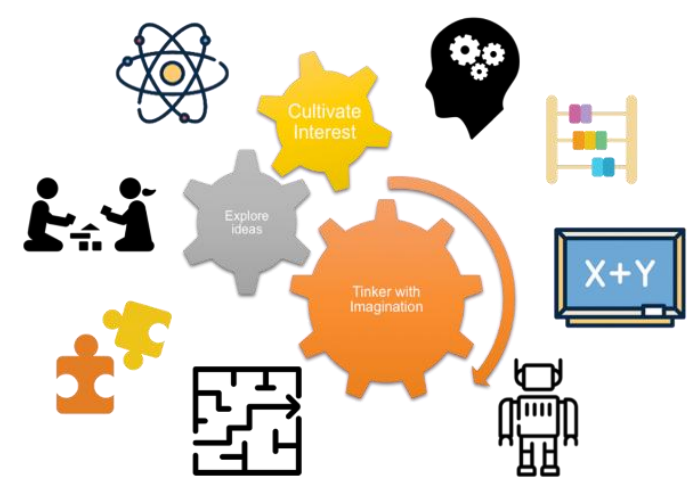

Figure 1: Exploring Technology

(Source : Google Image) [2]

\section{REVIEW OF LITERATURE}

The advancement in technology has led to the exploitation of resources in order to gain the maximum knowledge [3]. Technology in education, meaning accession to digital tools such as laptops, mobile phones plays a significant role in student's life [4].

However, many studies and Meta-analysis have been done that shows both positive and negative effects of technology in Education and also the effects of digital tools on the students.

\subsection{Kulik's Meta-Analysis}

Meta analysis on 500 students was done based on computer instructions to determine the process of education in order to understand about the student's interest, their needs, and their pre- existing knowledge. The results found were both positive and negative. Kulik et al. found the 64 percentile achievement in tests for the students who used computer based instructions as compared to the students who scored 50 percentile without computers. Also the students with computer based instructions evolve with more optimistic behavior along with more learning power in very less time. But some areas were observed with lower percentile score or gain upon use of computer based instructions. For example- In elementary and school education 44 studies were analyzed but only 14 percentile gains was observed over control group [5].

\subsection{Sivin- Kachala Review of Research}

This study provided with the information on how technology affects the achievement of student, their interactions with educators in enriched learning environment and reached to the conclusion of positive results. Students with computer based instructions (technology) achieved more in all subject areas, positive attitude in learning and their self-concept become more clear [6].

\subsection{Apple Classrooms of Tomorrow}

A type of collaboration which takes into account the public schools, universities, research institutions/agencies and Apple computer where students and teachers are allowed to access the wide range of tools and technology, software programs. This research illustrated the great potential for learning in students, their thoughts, ideas, representation in a better way when they have an access to technology. Also, the coordination among students, involvement of students with teachers, motivation has been improved significantly [7]. Although, they were lacking in some standardized tests such as vocabulary, problem solving skills, mathematical concepts, reading comprehension $[7,8]$.

\subsection{West Virginia's Basic Skills/Computer Education (Bs/Ce) Statewide Initiative32}

This study was approved in 1989-1990. They started with the class Kindergarten in 1990-1991. Installation of hardware and software was done in schools and process of providing professional skills began. The basic components of this study include software for governing skills like mathematics, reading, lingual arts; computers in schools for the better access to software and the instructions based training for teachers in context of software and computer used. This study also tells about the conditions under which technology is effective in the process of advance learning and teaching.

Data was collected from 950 students, belonging to grade 5 and from 290 teachers from about 18 elementary schools. Both students and teachers had been participating in the Way Virgine BS/CE since 1991-1992 and it have been found that 
the students who participated more I'm BS/CE scored more in the test on Stanford 9. They developed an optimistic behavior towards the technology and the training and professional skills provided to the teachers led to the more potential and achievement gains to the students. The main advantage of this study is that it was found to be very cost effective [9].

\subsection{Harold Wenglinsky's National Study of Technology's Impact on Mathematics Achievement}

In this study, data was collected from fourth grade students $(6,227)$ and eighth grade students $(7,146)$ in order to determine the impact of educational technology on student's Mathematics based on the National Assessment of Educational Progress. The study consisted of the information on the number of times computer was used for Mathematics in school, computer access either in home or school, training to mathematics teacher for the computer use and the computer based instructions to students in schools. From this information, Wenglinsky found that the students and teachers of eighth grade who used computer for Mathematics gain more scores of up to 15 weeks and 13 weeks respectively above grade levels as measured by National Assessment of Educational Progress, reveling the use of computer simulations/math learning games, professional training had powerful and positive impact on achievement of both fourth and eighth grade students in Mathematics. However, for the students of fourth grade students who used computers for the purpose of math or other math related learning games gain score of upto 3-5 weeks above grade level [10].

\subsection{Scardamalia \& Bereiter's Computer Supported Intentional Learning Environment (Csile) Studies}

CSILE allows the students to create a database that consists of their ideas, queries, and opinions in the form of images, pictures and written notes and in this way CSILE supporting the intentional learning among the students. Students from any grade level can access 33CSILE. CSILE captured the different thoughts of different students and makes them available to everyone so that any student can access them. This research was mainly concerned with the pre-existing knowledge of the students and do that knowledge develop them into successful or unsuccessful individual.

Research for about 8 years has showed that CSILE students were more superior to the non CSILE students in terms of standardized test including vocabulary, reading, language; self-dependent thoughts; comprehensive understanding; viewpoints etc. [11].

\section{METHODOLOGY}

The Survey was conducted through an online portal called google forms in which students belonging to universities in Delhi-NCR. This online survey began on $17^{\text {th }}$ January 2019 to $30^{\text {th }}$ January 2019 resulting into 300 responses. The software WEKA is used for result analysis.

\subsection{Research goals}

The main goals of this research are:

- How students evaluate the use of technology in education?

- The technical conditions within University in order to enable the use of technology in teaching.

- At what level technology is involved in teaching and learning [1].

\section{RESULTS \& DISCUSSIONS}

A questionnaire on learner use of technology was distributed online through their emails to various universities student in Delhi-NCR region (Delhi Technological University, MRIIRS, MRU, Amity University, DCRUST, GGSIPU, PDM, Maharaja Surajmal Institute of Technology, MDU, B S Anangpuria, IGNOU, SGT, University of Delhi, Central University of Rajasthan and Baba farid institute of technology). The data obtained from 300 instances were observed in which a total count of 17 attributes attributes were considered like their background Information, country, gender, age group, level of study, year of study, faculty discipline, physical or learning disability, courses that they are currently studying, access to the Internet at, access to the Internet through, device for internet used, broadband Internet connectivity, if they get access to broadband Internet in their institution, Wi-Fi/wireless Internet connectivity on their campus, if they use the internet and have an account on a social media (Figure 2-10). WEKA tool was used for analysis of data.

A minimum support of 0.85 (255 instances) was provided. Minimum metric <confidence>: 0.9 was used and number of cycles performed was 3 . Hence it can be inferred from the above data obtained that the individuals who used internet daily was 276 , out of which 267 had accounts on social media where <conf:(0.97)> lift:(1.01) lev:(0.01) [2] conv:(1.1). It was supposed that there were no individuals with physical or learning disability and 364 individuals were using internet daily among which 255 had active social accounts where <conf:(0.97)> lift:(1.01) lev:(0.01) [1] conv:(1.06) while 287 students with no disability had 276 socially active accounts where <conf:(0.96)> lift:(1) lev:(0) [0] conv:(0.96). On the other hand the number of individuals who used internet regularly with no physical and learning disability was 264 , where <conf:(0.96)> lift:(1) lev:(-0) [0] conv:(0.92) (Figure 210). Therefore, it can be stated that technology directly or indirectly has improvised the education system, learning techniques, and real life interactions socially and digitally among the people of all age groups through any possible devices or gadgets and accessing social networking sites regularly through broadband connections at their home or from their working places. 


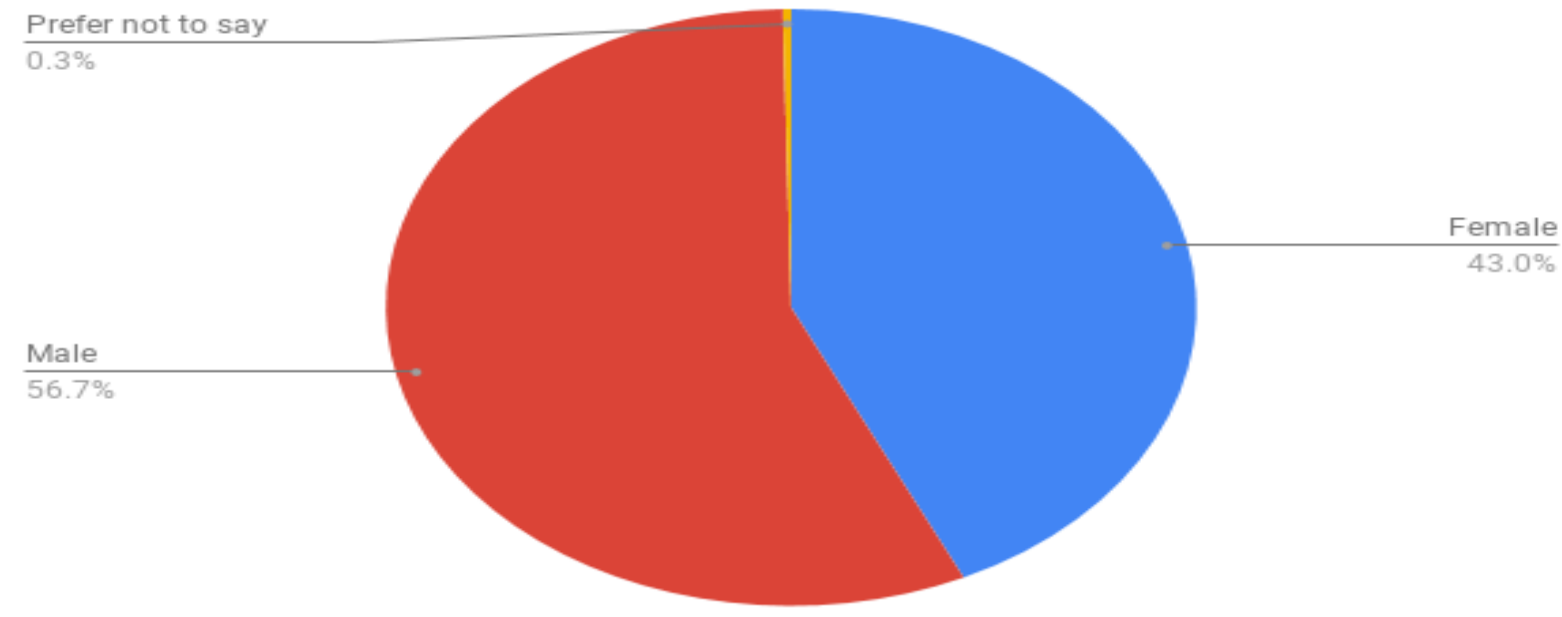

Figure 2: Gender

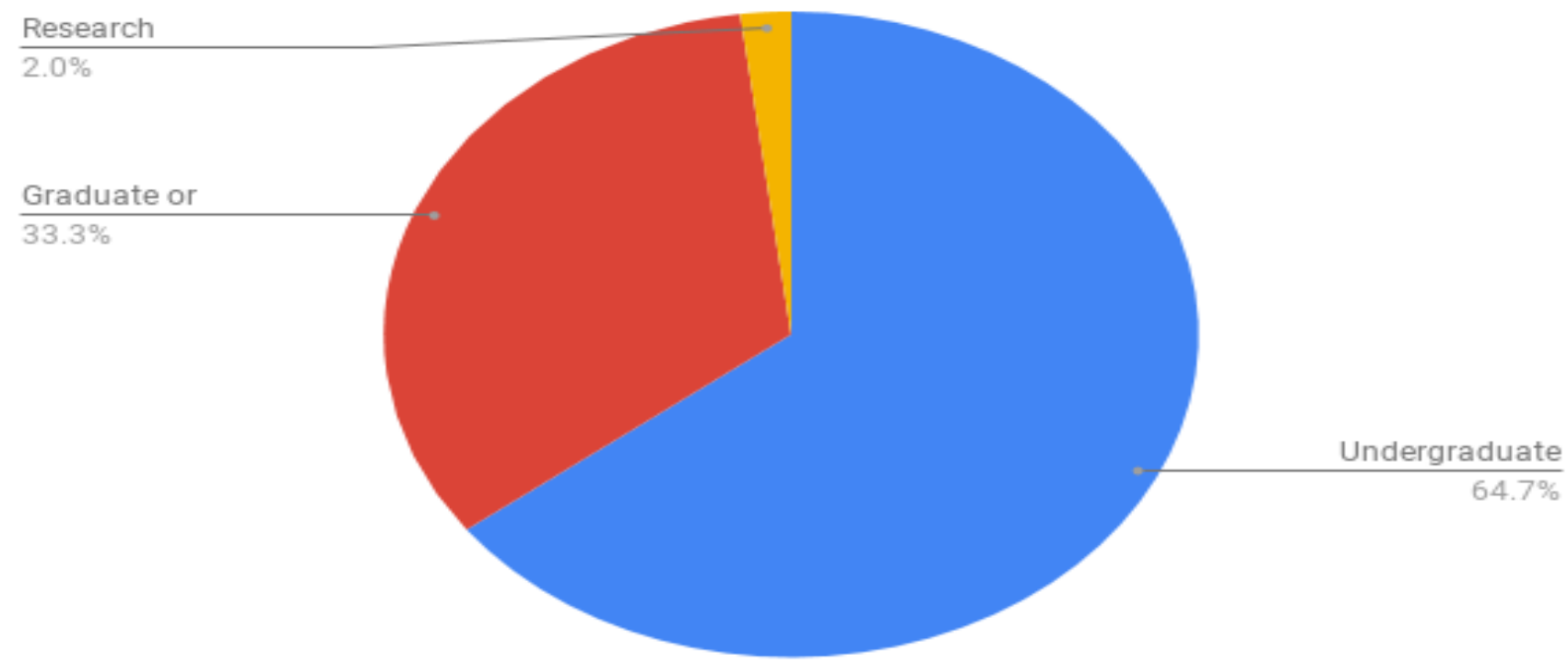

Figure 3 Level of Study

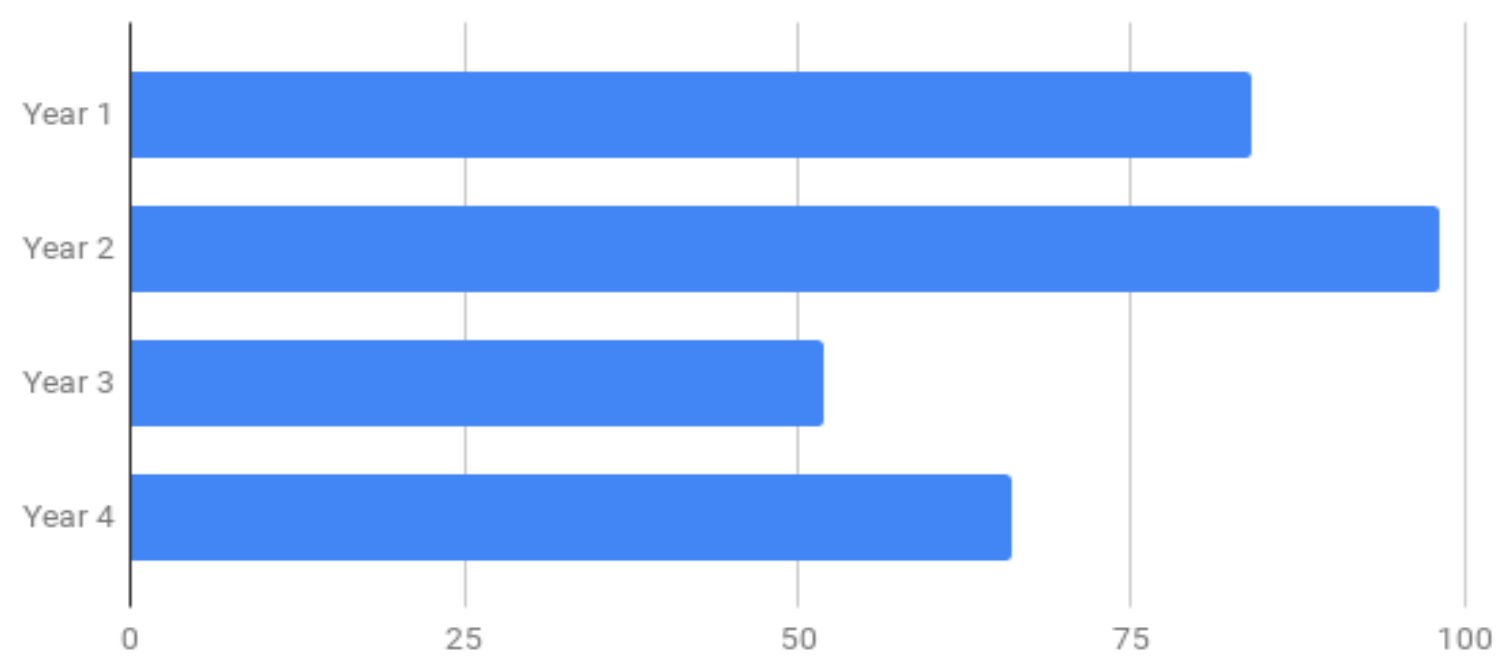

Figure 4 Year of Study 


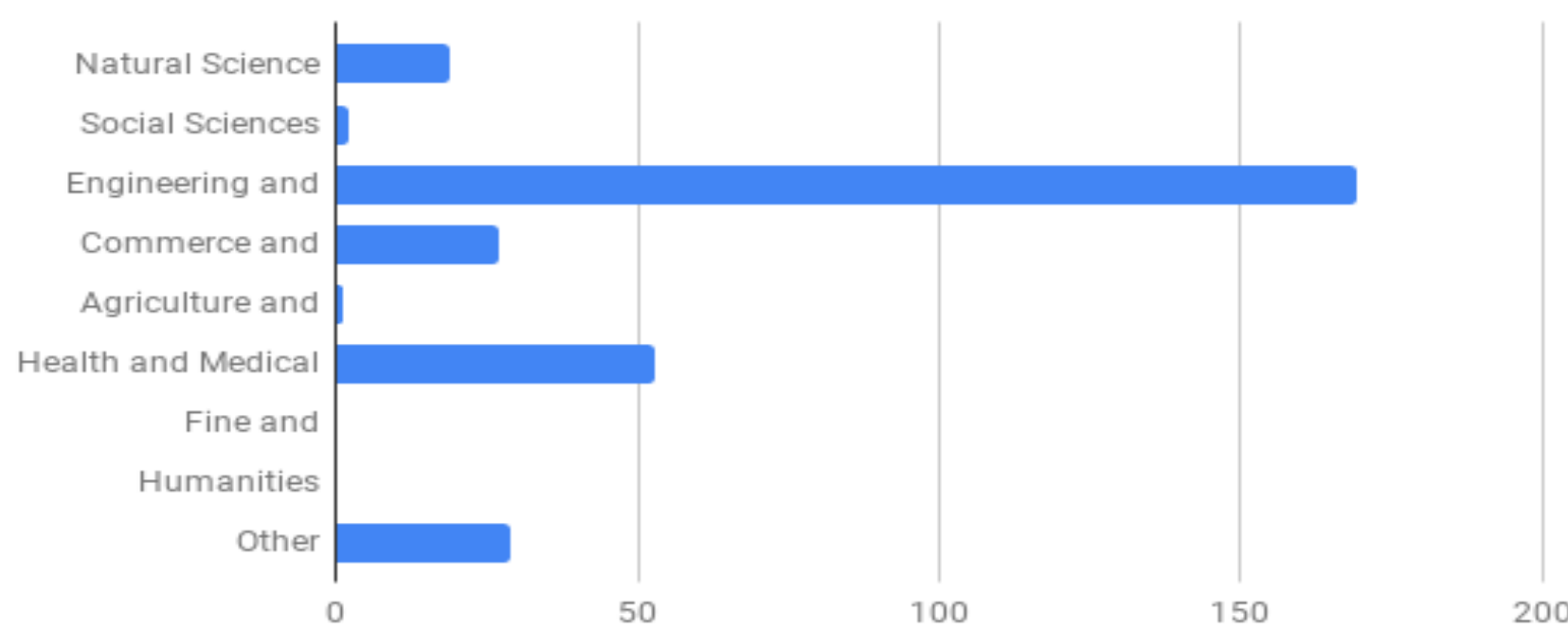

Figure 5 Faculty discipline

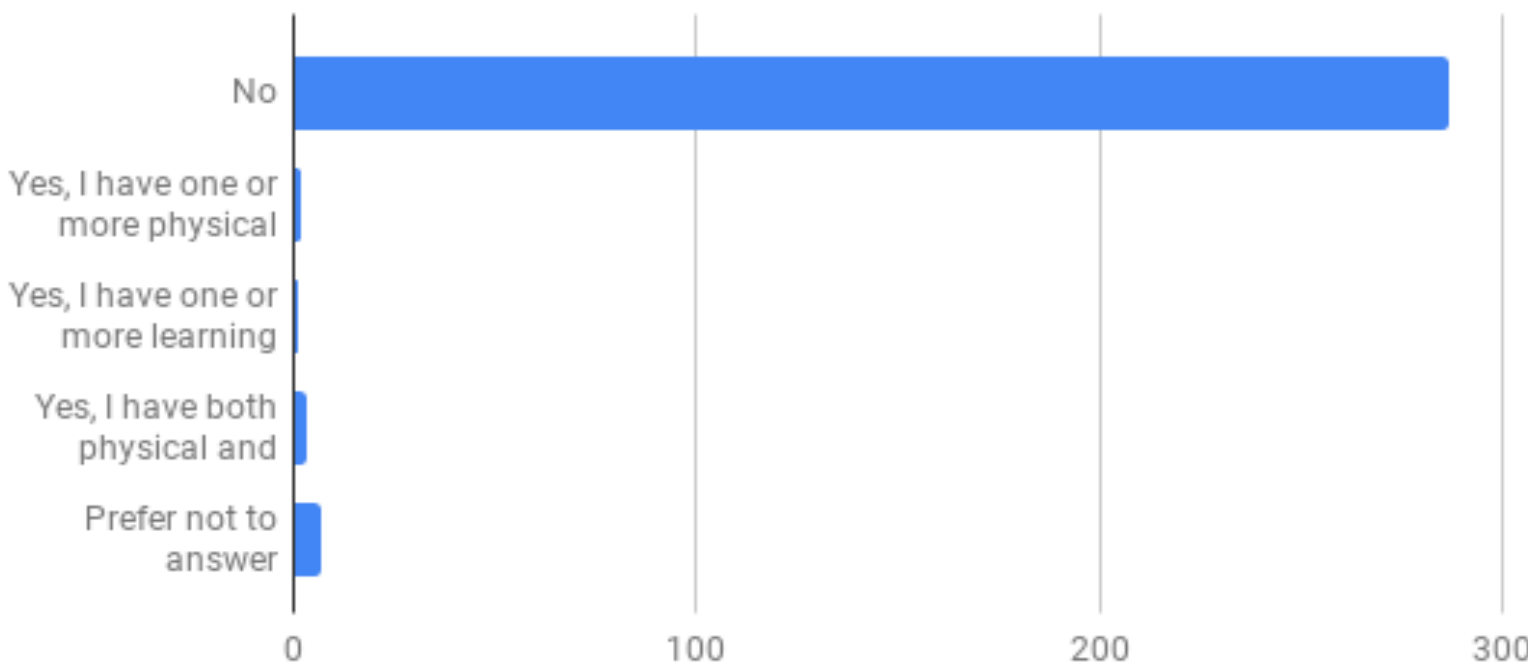

Figure 6 Any physical or Learning disability

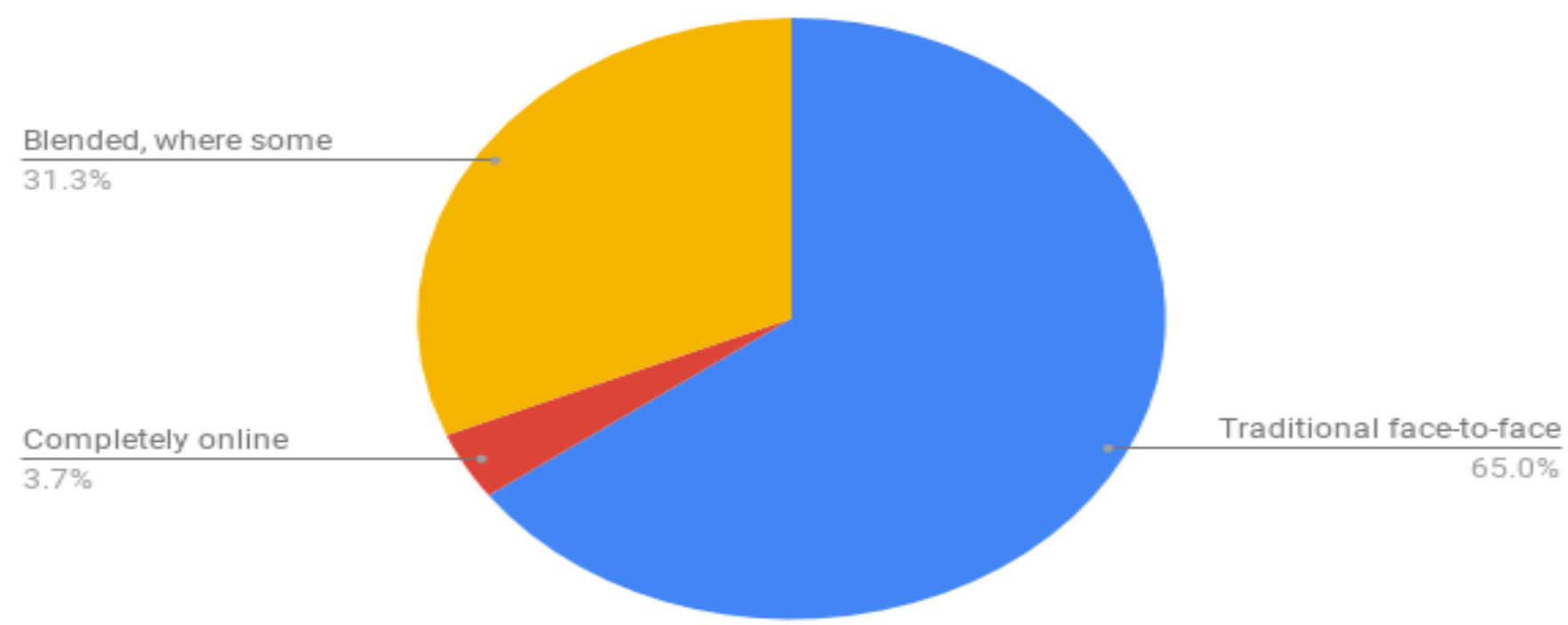

Figure 7 Course currently Studying 


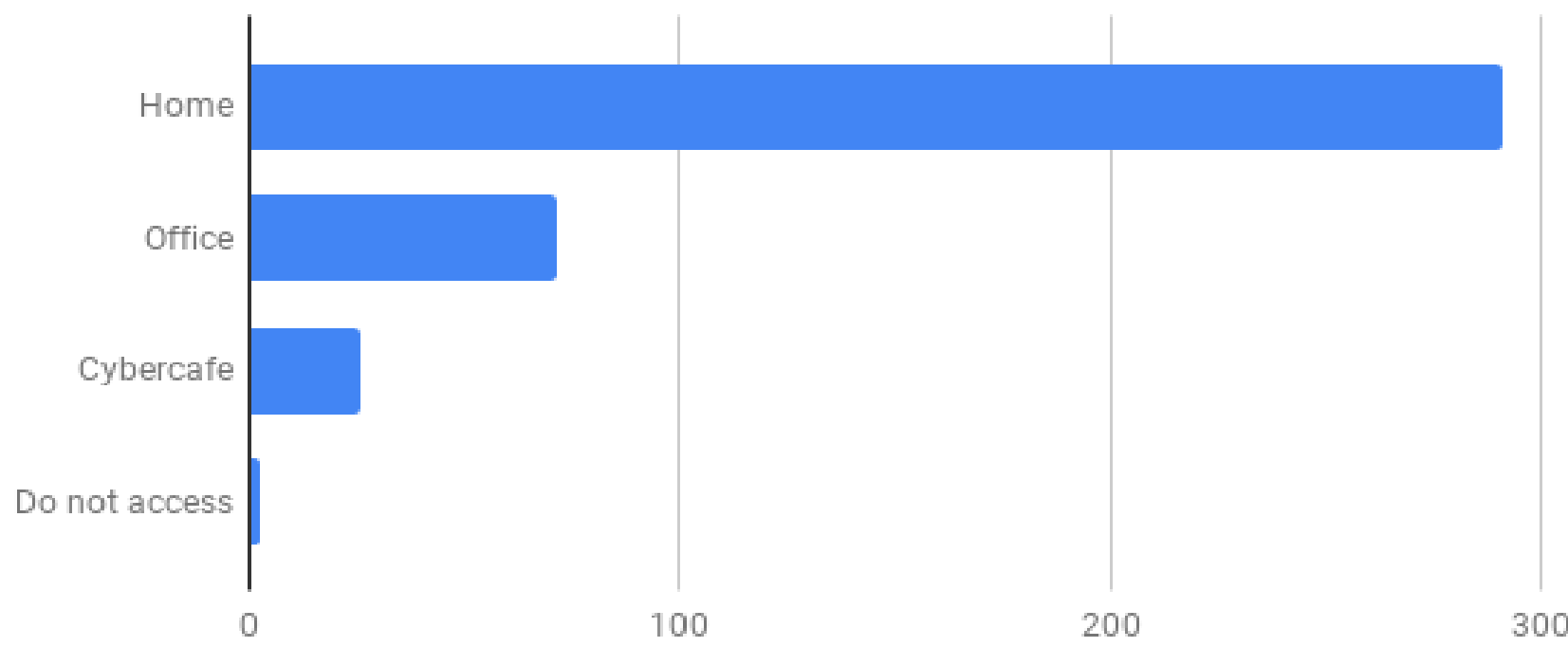

Figure 8 Access of Internet
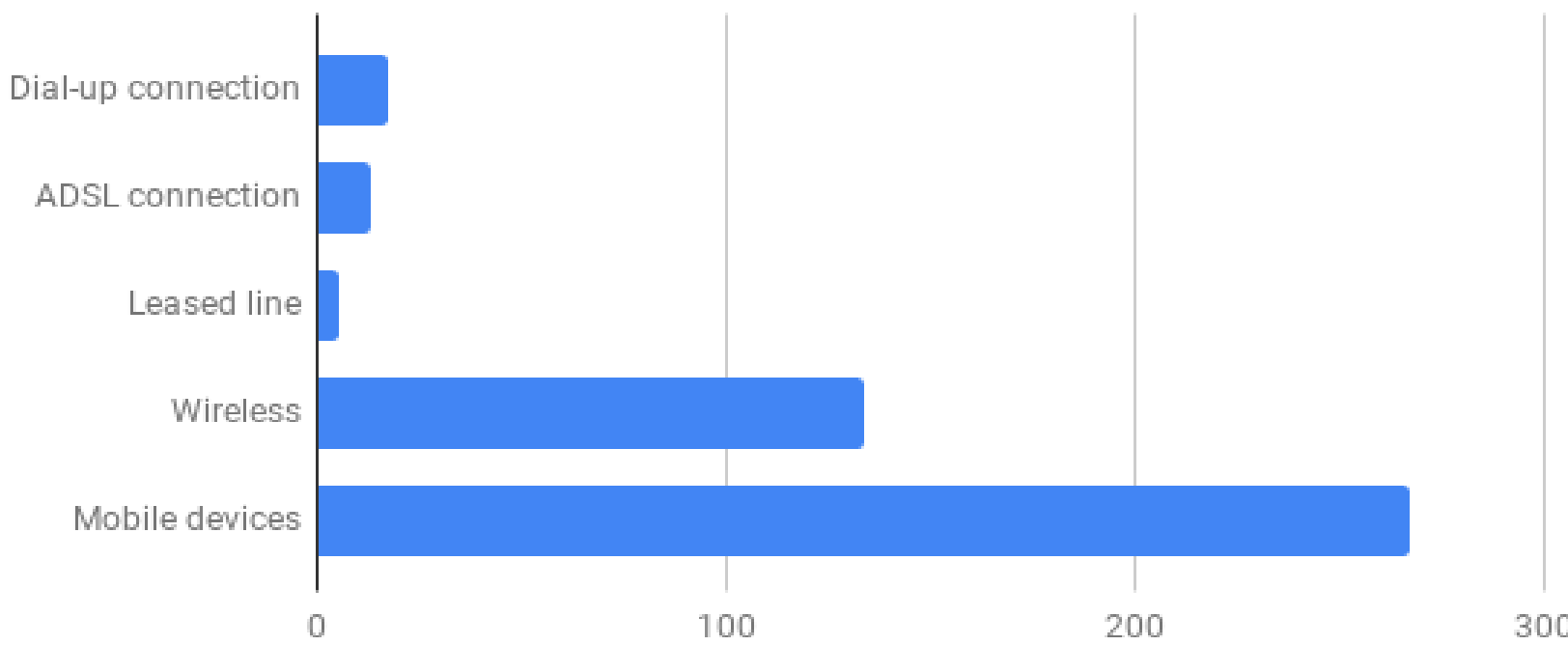

Figure 9 Access of Internet through

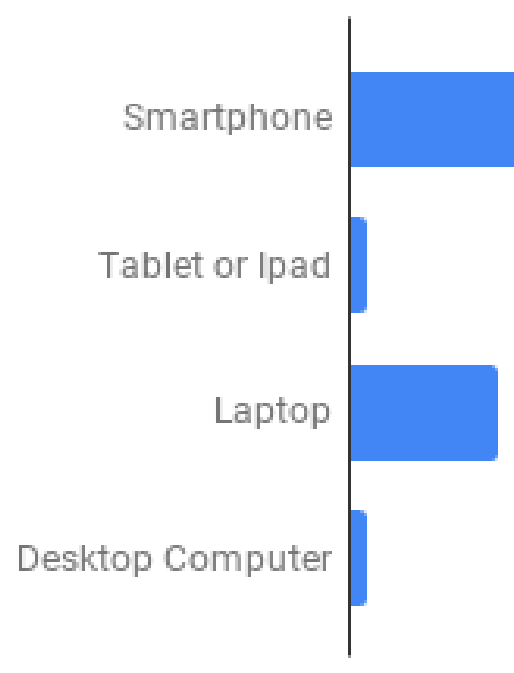

0

100

Figure 10 Devices used for Internet 


\section{ACKNOWLEDGEMENTS}

I would like to acknowledge Dr. Hardev Thakur, Associate Professor in the department of Computer Science \& Technology, Manav Rachna University; Dr. Pushpa C. Tomar and Dr. Sunita Bansal, Associate Professor in the department of Biotechnology and Civil department respectively, Manav Rachna International Institute of Research \& Studies and for their constant support and dedication.

\section{REFERENCES}

[1] Blerim, B. and Florim, I. 2015. A survey an effective use of information technology in high schools, European Journal of Research and Reflection in Educational Sciences, 3(4):1-8.

[2] https://www.google.com/url?sa=i\&source=images\&cd= $\&$ cad=rja\&uact $=8 \&$ ved $=0$ ahUKEwi 25 uPAypXjAhVFU 30KHU3QD8AQMwhOKAswCw\&url=http\%3A\%2F\% 2Fwww.trcmarin.org\%2Fservices\%2Fexplore-techday\&psig=AOvVaw0AlcmNNjuzZ71jGCvSvqZP\&ust= 1562134466507538 \&ict $x=3 \&$ uact $=3$

[3] Erstad, O., Kløvstad, V., Kristiansen, T., and Søby, M. 2005. Digital Skole Hver Dag - Om Helhetlig Utvikling av Digital Kompetanse i Grunnopplæringen (Norwegian Centre for ICT in Education).

[4] Stakkestad, S.V. and Størdal, G.F. 2017. The Ełects of Technology on Students' Academic Performance. Master Thesis, Economics. Norwegian School of Economics. Bergen, Autumn., 1-56.

[5] Kulik, J.A., Kulik, C.L.C. and Cohen, P. A. 1980. Effectiveness of Computer-generated based College
Teaching: A Meta- analysis of Findings. Review of Educational Research. 50(4); 535-544.

[6] Kachala, J.S., Bialo, E.R., and Langford, J. 1997. The Effectiveness of Technology in Schools, '90-'97. Report. Non- Journal. 1997: 88p.

[7] Ringstaff, C., and Yocam, K. 1997. Apple Computer, Inc. Integrating Technology into Classroom Instruction: An Assessment of the Impact of the ACOT Teacher Development Center Project. Jean Marsh Independent Educational Research. 1-16.

[8] John Schacter. THE IMPACT OF EDUCATION TECHNOLOGY ON STUDENT ACHIEVEMENT: WHAT THE MOST CURRENT RESEARCH HAS TO SAY. $1-10$

[9] Dale Mann, Charol Shakeshaft, Jonathan D. Becker, Robert Kottkamp (1999). WEST VIRGINIA STORY: ACHIEVEMENT GAINS FROM A STATEWIDE COMPREHENSIVE INSTRUCTIONAL TECHNOLOGY PROGRAM. Educational Leadership Faculty Publications, 1-46.

[10] Wenglinsky, Harold (1998). DOES IT COMPUTE? THE RELATIONSHIP BETWEEN EDUCATIONAL TECHNOLOGY AND STUDENT ACHIEVEMENT IN MATHEMATICS

[11] Marlene Scardamalia, Carl Bereiter, Robert S. Mc Lean, Jonathan Swallow, Earl Woodruff (1989). COMPUTER-SUPPORTED INTENTIONAL LEARNING ENVIRONMENTS. J. Educational Computing Research, 5(1):51-68. 